\title{
Os múltiplos extermínios dos corpos negros pela violência de linguagem: Uma reflexão das Fake News sobre Marielle Franco ${ }^{1}$
}

\author{
Los múltiples exterminios de los cuerpos negros por la violencia del \\ lenguaje: Una reflexión de las Fake News sobre Marielle Franco
}
The Multiple Exterminations of Black Bodies by Violence of Language: A Fake News Reflection on Marielle Franco

\section{Ludmila Pereira de Almeida ${ }^{2}$}

\begin{abstract}
Resumo
A militância política, atualmente, tenta encontrar seu discurso na reivindicação, no desafio da injustiça e, talvez, na enunciação das minorias, tomando seu lugar nas interações políticas atuantes. Nesse sentido, a atuação de Marielle Franco marcou uma posição de enunciação (BENVENISTE, 2006), isto é, o discurso-ato apropriou-se de um corpo politicamente ativo e falou por si, mesmo sendo nomeada de radical, por espaços e discursos dominantes. Seus enunciados tencionaram a conduta social do bom convívio e da cordialidade dos "cidadãos do bem", os mostrando manifestantes de discursos de ódio. Com o assassinato de Franco ficou claro que, para sobreviver, pelo menos, a enunciação não pode ser um ato discursivo completo e, por conseguinte, não deve passar de um discurso generalizado ou esquivo da realidade. Após o assassinato da vereadora do Rio de Janeiro, o seu lugar de enunciação tentou ser contradito pela ideologia textual Fake News. As Fake News recortam questões reais para fazer enunciados infundamentados, com "seriedade informativa", uma contra enunciação bem planejada e sustentada pela desinformação séria. Nessa perspectiva, nosso trabalho visa discutir os parâmetros discursivos das Fake News sobre Marielle Franco, considerando não só o seu ativismo, mas também o que o seu corpo simboliza face à estrutura social-racial brasileira (DJAMILA, 2015). Assim, propomos um olhar interseccional (CRENSHAW, 2002) sobre o corpo negro e as práticas de linguagem sobre ele que desembocam em contra enunciações, tensões e ideologias linguísticas que organizam o que é considerado "verdade", e até quem pode/deve viver e morrer. Tanto que tal caso não é isolado, coincidentemente o homicídio de mulheres negras aumentou (MAPA DA VIOLÊNCIA, 2015) junto ao surgimento de movimentos sociais feministas e suas várias necessidades. Portanto, observamos o quanto as múltiplas execuções de um corposímbolo de esperança contra-hegemônica é projetado na mídia dominante, de forma que a construção colonial de uma memória, de um corpo físico e simbólico, passa a ser a representação de todo o grupo do qual faz parte.
\end{abstract}

Palavras-chave: Marielle Franco; Fake News; contra-enunciação; decolonialidade.

\section{Resumen}

Actualmente, la militancia política intenta encontrar su discurso en la reivindicación, en el desafío de la injusticia y, tal vez, en la enunciación de las minorías, tomando su lugar en las interacciones políticas actuantes. En este sentido, la actuación de Marielle Franco marcó una posición de enunciación (BENVENISTE, 2006), o sea, el discurso-acto se apropió de un cuerpo políticamente activo y habló por sí, aun siendo tildada de radical, por espacios y discursos dominantes. Sus enunciados colisionaron con la conducta social de la buena convivencia y de la cordialidad de los "ciudadanos de bien", los exponiendo como manifestantes de discursos de odio. Con el asesinato de Franco quedó claro que, para sobrevivir, por lo menos, la enunciación no puede ser un acto discursivo completo y, por consiguiente, no debe pasar de algo generalizado o esquivo de la realidad. Después del asesinato de la regidora de Rio de Janeiro, su lugar de enunciación fue contestado por la ideología textual Fake News, una "tipología" que no se puede considerar ni verdad, ni mentira, ni ironía. Las Fake News recortan

\footnotetext{
${ }^{1}$ A primeira versão desse artigo foi apresentado e publicado nos anais do II Seminário Latino-Americano de Estudos em Cultura - SEMLACult em Foz do Iguaçu/PR, Brasil, 2018.

2 Doutoranda em Linguística pelo Programa de Pós-Graduação em Letras e Linguística, da Faculdade de Letras da Universidade Federal de Goiás-UFG; Goiânia, Goiás, Brasil; Bolsista CNPq. E-mail: ludmilaletras@gmail.com.
} 
problemáticas reales para elaborar enunciados sin fundamentos, con "seriedad informativa", una contraenunciación bien planeada y sostenida por la desinformación seria. En esta perspectiva, nuestra investigación quiere discutir los parámetros discursivos de las Fake News sobre Marielle Franco, no solamente considerando su activismo, sino también lo que su cuerpo simboliza, vista la estructura social-racial brasileña (DJAMILA, 2015). Así, proponemos un enfoque interseccional (CRENSHAW, 2002) sobre tal cuerpo negro y las prácticas del lenguaje sobre él que desembocan en contra-enunciaciones, tensiones e ideologías lingüísticas que organizan lo que es considerado verdad y, hasta quién puede/debe vivir o morir. Al punto que tal caso no es aislado, coincidentemente, el homicidio de mujeres negras aumentó (MAPA DA VIOLÊNCIA, 2015) junto al surgimiento de movimientos sociales feministas y sus múltiples necesidades. Por lo tanto, observamos la intensidad de cómo las varias ejecuciones de un cuerpo símbolo, de esperanza contra hegemónica, están proyectadas en la media dominante, de forma que la construcción colonial de una memoria, de un cuerpo físico y simbólico, pasa a ser la representación de todo el grupo del que forma parte.

Palabras clave: Marielle Franco; Fake News; contra-enunciación; descolonialidad.

\begin{abstract}
Political activists now try to find their discourse in the claim, in the challenge of injustice and, perhaps, in the enunciation of minorities, taking its place in the active political interactions. In this sense, the performance of Marielle Franco marked a position of enunciation (BENVENISTE, 2006), that is, the speech-act appropriated a politically active body and spoke for itself, even if it is called radical, by spaces and dominant discourses. His statements reached the social conduct of good fellowship and the cordiality of the "citizens of good", showing them demonstrators of hate speeches. With Franco's assassination it was clear that in order to survive, at least, enunciation can not be a complete discursive act and therefore should not be a generalized or elusive discourse of reality. After the assassination of the councilwoman of Rio de Janeiro, her place of enunciation tried to be contradicted by the textual ideology Fake News. The Fake News cut real issues to make unsound statements, with "informative seriousness," a well-planned counterattack and sustained by serious misinformation. In this perspective, our work aims to discuss the discourse parameters of the Fake News about Marielle Franco, considering not only its activism, but also what its body symbolizes in relation to the Brazilian social-racial structure (DJAMILA, 2015). Thus, we propose an intersectional view (CRENSHAW, 2002) on the black body and the language practices on it that lead to counteractions, tensions and linguistic ideologies that organize what is considered "truth", and even who can / should live and die. So much so that this case is not isolated, coincidentally the murder of black women has increased (MAP OF VIOLENCE, 2015) with the emergence of feminist social movements and their various needs. Therefore, we observe how much the multiple executions of a body-symbol of counter-hegemonic hope is projected in the dominant media, so that the colonial construction of a memory, a physical and symbolic body, becomes the representation of the whole group of which it is a part.
\end{abstract}

Keywords: Marielle Franco; Fake News; opposite-enunciation; decoloniality.

Eles combinaram de nos matar, mas nós combinamos de não morrer. Conceição Evaristo

\title{
1. Considerações iniciais
}

No dia 14 de março de 2018, a militante e vereadora do Rio de Janeiro, Marielle Franco, foi cruelmente executada. Até as últimas redações da nossa pesquisa, as autoridades e 
sua rede de investigação apontam o envolvimento de milícias de suspeitos próximos à família do atual presidente do país ${ }^{3}$.

Marielle era negra, feminista, lésbica, mãe, esposa, nascida e criada no Complexo da Maré - Rio de Janeiro, graduada em sociologia e mestre em Administração Pública. Foi a quinta mais votada nas eleições para a cidade do Rio de Janeiro, sendo eleita vereadora pelo PSOL com 46,5 mil votos. Após isso, foi nomeada relatora da Comissão dos Vereadores que fiscaliza a intervenção militar no Estado carioca, diante da qual não se mostrava favorável e sempre se posicionava diante dos avances violentos contra os moradores. Foi uma eleição marcada ativamente pela comunidade que se mostrava favorável tanto à trajetória da vereadora quanto depositavam nela uma forma da favela ser ouvida. Franco foi uma das 32 mulheres negras eleitas vereadoras nas capitais brasileiras em 2016, 3,9\%, de um total de 811 vereadores eleitos nas capitais do país.

Ao compor parte de um número extremamente pequeno dentro do espaço legislativo, ao consideramos o déficit que sofre a representação do povo negro, que forma mais da metade da população do Brasil, aponta de início, que o lugar em que Franco ocupava era um lugar dado historicamente para poucos. Ao demandar lugar de poder, o parlamento é um executorpropositor de ações que interferem na estrutura social do país, portanto ter uma mulher negra trazendo a demanda de seu povo, que não é a mesma demanda de quem mora no Leblon, incomodava e incomoda por ser o 'direito de falar' algo barrado historicamente.

As mulheres negras se situam na base da sociedade ao serem marcadas por múltiplas diferenças hierarquicamente impostas como naturais. Categorias de raça, gênero, classe, escolaridade perpassam esses corpos e os massacram a partir da invenção de um ideal de humanidade que não as abarca.

Para Bruna Cristina Jaquetto Pereira, doutora em sociologia pela Universidade de Brasília que estuda a violência contra a mulher negra, "a maior parte dos movimentos de base no Brasil são compostos por mulheres negras". "Tem-se a falsa ideia de que as mulheres negras não participam da política, mas elas são as que lidam diretamente com os problemas estruturais da sociedade brasileira. Elas se mobilizam no nível mais básico, fazendo a política do cotidiano, desde a participação em associações de bairro até a mobilização em grupos contra a violência de jovens negros assassinados, seus filhos." (GRAGNANI, 2018, s/p).

Dessa forma, existir é também um ato político, pois incomoda os da casa grande e fornece esperança de transformação das realidades que se encontram subjugadas ao padrão de

\footnotetext{
3 Ver mais em: "O elo entre Flávio Bolsonaro e a milícia investigada pela morte de Marielle". Disponível em: https://brasil.elpais.com/brasil/2019/01/22/politica/1548165508_401944.html. Acessado em: 17/05/2019; "Xadrez do elo perdido que liga Flávio Bolsonaro a Marielle, por Luis Nassif”. Disponível em: https://jornalggn.com.br/direitos/xadrez-doelo-perdido-que-liga-flavio-bolsonaro-a-mariele-por-luis-nassif/. Acessado em: 17/05/2019.
} 
existência, saber e ser. O Brasil ao nascer da violência e viver às custas disso, homogeneíza o seu espaço-tempo como forma de divulgar a harmonia superficial sob o massacre dos povos tidos como não importantes para o progresso científico-tecnológico, no entanto, se precisam desses mesmos povos para movimentar a estatística econômica e sustentar a pirâmide da desigualdade.

A própria noção de história oficial aponta isso ao apagar os povos originários e escravizados como produtores de conhecimento, como construtores e enriquecedores desse espaço. Tanto que racismo e modernidade são atos intrínsecos (QUIJANO, 2005), pois surgem com a invenção do outro e seu silenciamento como higienização da noção de humanidade. "O comércio transatlântico de africanos inaugura de uma só vez a geopolítica da exploração e a naturalização jurídica do sujeito sem direito. Não haveria condições para a ascensão da ordem burguesa não fosse pela violência do tráfico transatlântico de seres humanos" (GASPAR; NOVO; OLIVEIRA, 2018).

Nesse sentido, executar Marielle, significou mais do que uma morte de seu corpo físico, mas uma forma de apontar o quanto esse corpo é "perigoso" ao deslocar do lugar ao qual foi segregado e do quanto a potência do ato de falar gera ódio. "O neoliberalismo chegou a um ponto que, para manter os processos de assujeitamento e exploração, precisa passar pelo extermínio de grupos, como um sistema neo escravocrata e um capitalismo mafioso" (BENTES, 2018, s/n). Um processo que une genocídio, etnocídio e memoricídio (RAMPINELLI, 2014) que tentam apagar com a insurgência e as reivindicações de direito à vida e à diferença.

É preciso lembrar de alguns marcos históricos que estruturam esse percurso de compreensão dos corpos no Brasil. Esse país foi o último das américas a abolir a escravatura; Compõe a segunda maior população negra do mundo; É a população que mais é morta no Brasil, segundo o Mapa da Violência de 2015, e compõe a quarta maior população carcerária do mundo. Franco ao contrariar às estatísticas usa do seu lugar de atuação militante no parlamento para mover os olhares para a intervenção militar no Rio e do quanto isso não resolveria o problema da violência, mas apenas a espetaculariza e gera gastos econômicos altos para o governo ${ }^{4}$. Sem contar no aumento de mortes de jovens negros da periferia a partir de uma visão do que é ser um "suspeito" no Brasil.

A polícia, é uma atualização de bandeirantes e capitães do mato, se assenta nesses dois zumbis coloniais, a escravidão (convertida em encarceramento); e a

\footnotetext{
4 Disponível em: https://g1.globo.com/rj/rio-de-janeiro/noticia/2018/12/27/intervencao-no-rj-deve-devolver-r120-milhoes-aos-cofres-da-uniao.ghtml. Acessado em: 17 de dezembro de 2018.
} 
pseudoabolição (convertida em pobreza), para honrar seu compromisso exclusivo de ostentar o monopólio oligárquico da violência. Nossas forças de segurança são um paradoxal mecanismo de exceção com existência jurídica, uma empresa fantasma do Estado oligárquico, que caça com adestrada precisão o inimigo interno da elite (GASPAR; NOVO; OLIVEIRA, 2018).

Ao ser criada na favela, a parlamentar sabia de como a atuação da polícia é incisivamente agressiva com qualquer pessoa, já que estão ali para garantir a proteção dos da casa grande. Tanto que ao ser eleita e ter um mandato pautado coletivamente, suas reivindicações se voltavam para um povo que até então não era ouvido e do qual só restava o medo diante da denúncia. Durante o seu mandato Franco sofria embates que a direcionavam a se calar diante dessa arquitetura da morte que se direciona à sujeitos específicos em espaços específicos dos quais a liberdade de ir e vir era pautada pela polícia.

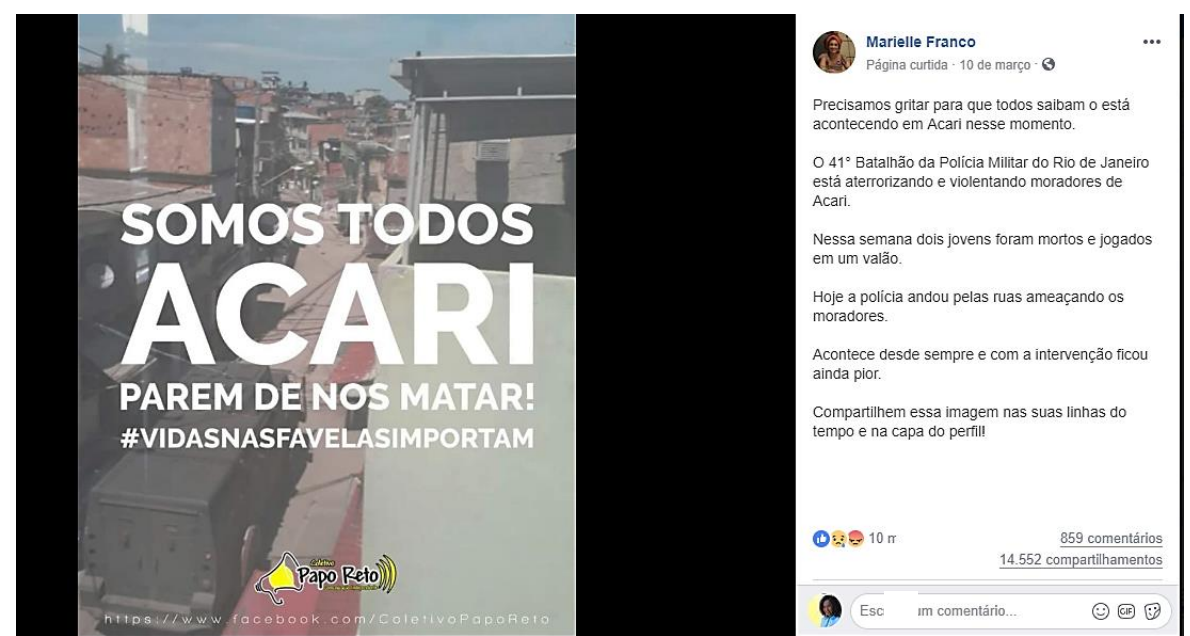

Fonte: Reprodução Facebook oficial Marielle Franco

E como se não bastasse a execução de Franco, logo após denúncias contra a intervenção militar, muitos comentários surgiram na mídia na tentativa de a culpar pela sua própria morte, além de construir narrativas-memórias por meio das Fake News ${ }^{5}$. Essas narrativas que discursam a imagem de Marielle Franco inferiorizam sua condição de moradora de favela, sua militância política voltada para o comunismo e a tentam ligar a bandidos, crime organizado, como sendo "mais um corpo de queima de arquivo". Duas, de várias notícias falsas, são essas abaixo feitas por pessoas atreladas ao poder executivo e parlamentar, que ocupam espaços de fala tidos como legítimos e próximos ao padrão de humanidade construído pelo eurocentrismo.

\footnotetext{
${ }^{5}$ Nossa pesquisa faz reflexões e questionamentos sobre este possível novo gênero textual, contextualizando-o na enunciação e na relação que esta constrói entre o espaço e o tempo do enunciado.
} 
Marilia Castro Neves A questão é que a tal Marielle não era apenas uma "lutadora"; ela estava engajada com bandidos! Foi eleita pelo Comando Vermelho e descumpriu "compromissos" assumidos com seus apoiadores. Ela, mais do que qualquer outra pessoa "longe da favela" sabe como são cobradas as dividas pelos grupos entre os quais ela transacionava. Até nós sabemos disso. A verdade é que jamais saberemos ao certo o que determinou a morte da vereadora mas temos certeza de que seu comportamento, ditado por seu engajamento politico, foi determinante para seu trágico fim. Qualquer outra coisa diversa é mimimi da esquerda tentando agregar valor a um cadáver tão comum quanto qualquer outro. Like - $2 d$

\section{CES 685}

Fonte: diariodocentrodomundo.com.br

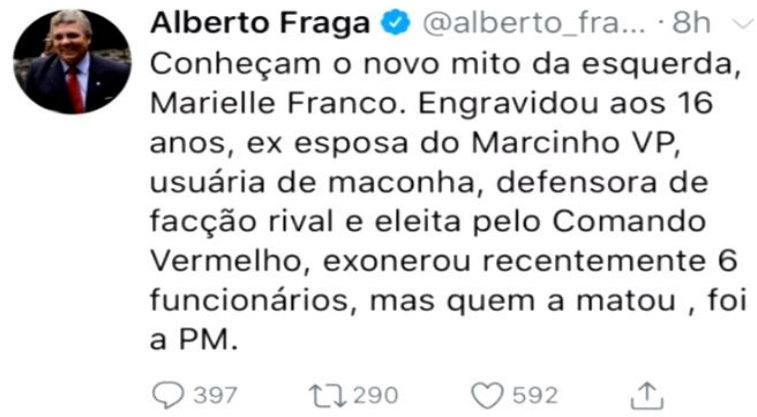

Fonte: Medium

Por isso, uma das discussões fundamentais do nosso trabalho é ver como as Fake News constroem a imagem enunciativa não só de Franco, mas do que ela representa e como a formulação dessa imagem tenta carregar uma suposta veracidade narrativa. Também perceber, dentro do pouco espaço aqui e traços ainda iniciais dessa discussão, como essas formas textuais conseguem se organizar midiaticamente ao "desinformar com seriedade", fazendo do discurso factual/investigado a fundo um contra-enunciado em tensão. Ademais, o assassinato de Franco trouxe à tona, novamente, a criminalidade dos corpos negros, já que não é comum se executar parlamentar no Brasil, porém quando se trata de um corpo antirracista, antiestrutura, se vê como "mais um caso".

Nesse sentido, trazemos algumas considerações da professora Kimberle Crenshaw (2002) quem considera que o corpo negro está sujeito a uma problemática complexa em interseccionalidades, de forma que as articulações de diferença, como a posição política, o gênero, raça, classe compartilham o mesmo corpo. Marielle Franco, como negra, lésbica, militante política e moradora da favela encontra sua complexa figura no campo interseccional, de múltiplas lutas contra a estrutura do poder. Questões que reverberam nos corpos que compartilham tais categorias de diferença, pois são corpos que também estão sendo exterminados e silenciados em prol de uma homogeneidade do saber/existir. 


\section{Enunciado, enunciação e "gênero textual Fake News"}

Propomos esta parte para estabelecer as relações entre enunciação como a representação de um corpo físico-linguístico-ideológico em movimento, em ação do dizer, no caso, o corpo-símbolo representativo de Marielle Franco. E o enunciado, como manifestação construída, é o dito sobre o mesmo corpo-símbolo, no caso, as Fake News sobre Franco. Igualmente, discutimos sobre a situação genérico-textual da narrativa Fake News (doravante $\mathrm{FN}$ ), posto que sua apresentação virtual acontece desde figuras falsas (fake) midiáticas, elaboradas em torno a supostas notícias que se mostram como verídicas, fazendo deste jogo uma (re)criação textual de uma memória.

\subsection{Enunciado, enunciação e dinamicidade do gênero textual}

Nos estudos linguísticos de Émile Benveniste, a posição dos sujeitos se mostra na sua atuação linguística e dos espaços de poder de quem diz e recebe o que se diz. Ao ser realizado/dito, o ato linguístico é chamado de enunciado. No entanto, o movimento desse enunciado provoca relações de linguagem das quais a enunciação se direciona a propósitos de contextualização que envolve o ato de sentido-significado. Dessa forma, a ação linguística se estabelece pela retomada histórica do que se é dito e do que isso pode provocar em quem ouve. Dessa relação sociolinguística, Benveniste formula a enunciação como um processo de apropriação da língua/linguagem e do quanto a produção de significado depende inclusive da trajetória histórica de quem ouve:

\footnotetext{
A língua se acha empregada para a expressão de certa relação com o mundo. A condição mesma dessa mobilização e dessa apropriação da língua é, para o locutor, a necessidade de referir pelo discurso, e, para o outro, a possibilidade de co-referir identicamente, no consenso pragmático que faz de cada locutor um co-locutor. A referência é parte integrante da enunciação (BENVENISTE, 2006, p. 84).
}

Nessa perspectiva, percebemos que a enunciação está em constante relação com o coletivo, ao invés de se individualizar, embora Benveniste mencione que existem muitos desdobramentos no contexto da enunciação como característica própria de seu estado dinâmico e transformacional. É nessa dinamicidade que podemos catalogar as FN midiáticas, como uma enunciação interligada e intersubjetivada pelo seu sujeito enunciador, mas também pelo grupo social que esse sujeito se encontra, e que embora siga características gerais de um diálogo coletivo, se estrutura no consenso único e pragmático do seu enunciador/locutor. 
No caso, as FN dispõem de uma estrutura enunciativa pragmática que proporciona fundamentos espaço-temporais para dizer o que querem dizer, desmesuradamente, não sendo considerado nisto que seu locutor construa uma enunciação dinâmica, mas um enunciado proposital, para modelar figuras com seu pragmatismo enunciativo. Por outro lado, em relação a se as FN se enquadrariam na tipologia ou gênero textual, tomamos algumas considerações do professor Luiz Marcuschi, nos seus estudos sobre os critérios classificatórios de tipologia, gênero ou domínios discursivos. A partir desses reconhecimentos, verificamos uma antecipada catalogação fundamental das FN. Assim, Marcuschi, ao considerar os estudos de Bakhtin sobre as formas narrativas, menciona que:

As definições aqui trazidas de gênero, tipo, domínio discursivo são muito mais operacionais do que formais e seguem de perto a posição bakhtiniana. Assim, para a noção de tipo textual, predomina a identificação de sequências linguísticas como norteadora; e para a noção de gênero textual, predominam os critérios de padrões comunicativos, ações, propósitos e inserção socio-histórica. No caso dos domínios discursivos, não lidamos propriamente com textos e sim com formações históricas e sociais que originam os discursos. Eles ainda não se acham bem definidos e oferecem alguma resistência, mas seguramente, sua definição deveria ser na base de critérios etnográficos, antropológicos e sociológicos e históricos (MARCUSCHI, 2008, p. 158).

Tomando em conta essas colocações, anotamos, a priori, que as FN seriam uma derivação genérica textual que se utiliza de vários formatos textuais para disseminar seu discurso. Porém, não encerramos a reflexão nesta primeira rotulação, mas seria preciso nos adentramos num trabalho posterior de forma mais complexa. Assim, podemos inferir, em primeira instância, que as narrativas sobre a imagem de Marielle Franco assumem ações e juízos de valor, de maneira proposital e dentro de um contexto socio-histórico demarcado. Além disso, não se pode esquecer que os enunciados movem discursos, muitos de ódio, que legitimam as FN como notícias, nem que sejam temporariamente, como verdadeiras e válidas para a distribuição.

\subsection{As Fake News}

A expansão dos recursos midiáticos, na atualidade, é uma das causas de interação global de notícias, antes limitadas pelo fluxo e pelo tempo de transporte; hoje, num movimento de pálpebras a notícia já está posicionada e distribuída na web. Porém, essa circulação goza de liberdade de parâmetros na sua elaboração, o que garante certa impunidade ao não exigir uma criteriosa veracidade dos fatos. Isto se deve à acessibilidade da web a vários públicos, posto que, mediante algumas estratégias simples, um indivíduo pode se tornar 
um editor e distribuidor de textos, sem necessidade de comprovar sua autenticidade e em questão de segundos.

É, nesse contexto - viral e virtual-real - que aparecem ${ }^{6}$ as Fake News (FN), ou na sua tradução, notícias falsas; narrativas de mundo que têm suas próprias caraterísticas genéricas e textuais para dada finalidade contextual. Por outro lado, as FN tampouco podem se categorizar como fato - já que tem sua fonte de elaboração e distribuição nos boatos, no exagero ou na especulação - nem tampouco na mentira, ao se alimentar de situações verídicas para sua des-in-formação, sem comprovar realmente se as informações são verídicas, distorcidas ou apenas uma nota feita para o espetáculo. É justamente esta não classificação o que chama a atenção nas FN, que usa dessa característica limiar para inscrever-se nos estudos do pós-verdade ${ }^{7}$.

Ao procurarmos uma aproximação conceitual informal das FN nos deparamos com a noção de que não são apenas notícias falsas, pois não é um acontecimento que surge nesse século, mas se alia, em especial, com a alta capacidade de viralização. As FN junto ao advento tecnológico das redes socais virtuais, tem a sua área de atuação intensificada e ampliada, a ponto até de organizar as pautas de conversa do dia a dia e desviar o foco de problemas sociais. De caráter, principalmente, opinativo as FN podem, muitas vezes, serem percebidas como mais um instrumento da colonialidade e da invenção do outro como controle da história. Isso porque informação investigada é poder e nem todos tem acesso à veracidade dos fatos ou se interessam por pesquisar sobre.

Isso mostra o quanto esse texto trabalha junto à "infantilização emocional" e cria mecanismos que faz com que poucas pessoas se preocupem em checar a origem da informação e suas nuances ideológicas. Ao estar muito ligada também ao prazer de se perceber representado, o consumo de FN pode se assemelhar ao uso de $\operatorname{drogas}^{8}$, ao gerar conforto imediato, anestesia da necessidade do diálogo e das tensões, e ao propiciar um ambiente de confiabilidade para o compartilhamento da "informação".

Um estudo recente do Instituto de Tecnologia de Massachusetts (MIT, na sigla em inglês), publicado na renomada revista Science, revelou que as fake news têm $70 \%$ mais chances de viralizar do que uma notícia real. Além disso, uma notícia falsa se propaga seis vezes mais rápido que uma notícia verdadeira. Segundo a doutoranda em Comunicação e Informação na Universidade Federal do Rio Grande do Sul, Taís

\footnotetext{
${ }^{6}$ Neste trabalho, não aprofundamos as aparições históricas das Fake News, mas só as abordamos perante sua divulgação nas mídias contemporâneas dos websites/internet, por nosso foco de estudo.

${ }^{7}$ Igualmente, não enfatizamos nossa pesquisa nas reflexões filosóficas do Pós-verdade, por motivos temáticos e temporais.

${ }^{8}$ Disponível em: https://www.bbc.com/portuguese/brasil-45767478. Acessado em: 27 de dezembro de 2018.
} 
Seibt, o motivo da rápida circulação e aderência das fake news é o tom sensacionalista e emotivo dessas mensagens (ALMEIDA e BTR, 2018).

O elemento discursivo básico que devemos considerar está na imprecisão enunciativa das FN, dúvida que se torna, às vezes, um benefício para quem as divulga. Algumas delas se valem pelo prestígio do meio informativo, causando desconfiança em organizações de imprensa que espalharam uma notícia dita exclusiva, sem corroborar as fontes. É preciso ainda observar que as FN são atos de fala (AUSTIN, 1998) que fazem e realizam coisas no momento em que são ditas, tanto que já nos deparamos com casos de mortes $^{9}$ devido a notícias falsas e a forte interferência nas decisões políticas de espaços que se nomeiam como democráticos.

O mal radical tem a dimensão de um projeto. Nele há um prazer em destruir. Um verdadeiro gozo perverso. Os donos do poder, governos e corporações, são seus sacerdotes. O cidadão comum faz parte desse projeto como uma espécie de "lacaio" que serve a um senhor. Ele é como o escravo digital que faz o mesmo papel do qual um robô é capaz, mas só o faz porque foi capturado por discursos orquestrados que o atingem no vazio previamente forjado pelos meios de subjetivação capitalistas, exímios esvaziadores de subjetividades (TIBURI, 2018).

Esse capturar pelo discurso retoma o tanto que é preciso um contexto e um objetivo para que as FN tenham efeitos de veracidade e viralize como verdade, e identificação com o que se é falado. É uma reconstrução da realidade que usa de elementos do momento para reentextualizar e recontextualizar ações e significados (SILVA, 2015), reorganizar as narrativas e a eximi-la de compromisso ético, é uma relação de força que só pode se romper por quem consegue ter um olhar crítico e se lançar ao diálogo - ato raro, que vai contra a estrutura e move tensões em uma sociedade de hierarquias que tem o egoísmo como norma. Por isso, o instrumento e ação que possibilita a elaboração e distribuição das FN é o uso da linguagem, quem a usa, quando se usa e sua possibilidade destruidora de apontar o que é fato.

\section{Violência pela linguagem, memoricídio e criminalização da diferença}

$\mathrm{O}$ ato de nomear é um ato histórico e de poder, isso marca o processo linear da história oficial que traz, por exemplo, os colonizadores como a "salvação" em combate aos "selvagens". Relatar a história foi por muito tempo um ato destituído de quem não era europeu ou não se aproximava dos padrões eurocêntricos de produção do conhecimento. Quijano (2005) aponta isso com a chegada da modernidade aliada ao racismo e do quanto esse processo parte de atos de linguagem científica que tentam "justificar" a diferença como

\footnotetext{
${ }^{9}$ Disponível em: https://www.uol/noticias/especiais/das-fake-news-ao-linchamento-como-uma-mentira-levou-amorte-de-uma-inocente.htm\#nunca-achei-que-fosse-possivel-uma-mentira-matar-uma-pessoa. Acessado em: 28 de dezembro de 2018.
} 
parâmetro de inferioridade. Segundo Butler (1997), o agenciamento do sujeito se dá através da interpelação do outro, um outro que concentra poder para realizar tal ação e se situa em um contexto que torne seu ato autêntico.

A corporificação do outro precede a sua existência e torna o ato ao qual foi nomeado como "natural", como destino, como violência epistêmica que legitima um modo de agir no mundo. A vulnerabilidade dos corpos ao ser controlada pela linguagem do fazer aliada a processos de invenção histórica sobre a diferença, interfere em necessidades básicas humanas como, por exemplo, o direito de ir e vir, de ser cidadão, regulando quais vidas "devem" ser menos vulneráveis, por serem posicionadas como "úteis" para o sistema político-econômico (BUTLER, 1997) e quais não atribuem importância para esse sistema.

A linguagem como ato de violência designa quem pode/deve viver e morrer (PINTO, 2016). E o corpo negro, que é nomeado à violência da exclusão, ao controle e vigilância pela manutenção do sistema, é um corpo que representa perigo ao poder em diferentes percepções. A opressão se desenvolve de acordo com as especificidades locais, porém, ritualiza a estrutura dominante construindo o signo negro como aquele que se relaciona à inferioridade (SEGATO, 2005). E quando esse corpo-signo, lançado à subalternidade decide falar e tem essa possibilidade de falar, causa incômodo pois abala toda a pirâmide da desigualdade (SPIVAK, 2012).

Por isso, o caso de Marielle Franco não é um caso isolado, nos últimos anos o homicídio e o encarceramento de mulheres negras aumentou (MAPA DA VIOLÊNCIA, 2015) junto ao surgimento de movimentos feministas e suas várias necessidades.

A morte de Marielle Franco faz ver que o ódio aos negros e às mulheres negras é um ódio fascista, ou seja, um ódio que não se contenta em matar. Na linha desse tipo de ódio, é preciso "exterminar" e é isso o que se faz quando se tenta usar sua memória e sua morte para conspurcar sua própria luta (TIBURI, 2018).

O extermínio como destruição do outro que é inventado por esse que quer destruir, é herança da fundação do Brasil, que nasce da violência e se sustenta disso. Os tentáculos da colonialidade, como esse processo constante de opressão que barra os sujeitos aos seus espaços de direito, que os extermina em suas múltiplas formas de existência, que recria o passado para que os povos negros não saibam a história dos reis e rainhas dos quais são descendentes, tem como instrumento as Fake News e o memoricídio como regra.

O memoricídio, por sua vez, consiste na eliminação de todo o patrimônio, seja ele tangível ou intangível, que simboliza resistência a partir do passado. Não apenas os deuses dos povos originários foram mortos, como as pirâmides superpostas por igrejas católicas, os templos pagãos trocados por mosteiros cristãos, os antigos palácios substituídos por mansões coloniais e as chinampas que abasteciam o 
mercado interno mudadas por grandes plantações voltadas para o externo. "Um povo sem memória", afirma Báez, "é como um homem amnésico: não sabe o que é nem o que faz e é presa eventual de quem o rodeia. Pode ser manipulado" (BÁEZ, p. 288). Controlar o passado é a melhor forma de planejar o futuro (RAMPINELLI, 2014, $\mathrm{s} / \mathrm{p})$

A própria história do Brasil cordial, de democracia racial, em que todos são iguais perante a lei, que há uma homogeneidade temporal-espacial das culturas, é uma enorme Fake News fomentada junto à máquina capitalista. E a mídia como potência de (re)criação das realidades, dos significados, compõe narrativas que pode tanto abalar quanto reforçar dadas trajetórias históricas.

Temos aqui duas faces do poder e da produção de subjetividades: as máquinas que se apropriam da potência dos corpos e sujeitos e que não necessariamente proíbem, aniquilam e reprimem; o sistema midiático e a sociedade de consumo tal qual conhecemos como poder soft que disputa imaginários, e o necropoder que desumaniza e aniquila (BENTES, 2018, s/n).

O racismo é um sistema de opressão, é um ato que imprime força sobre um coletivo, mesmo quando se dirige, aparentemente, a um indivíduo como foi com Franco. A cobertura midiática de sua morte nos grandes meios de comunicação teve como foco a produção de mais uma notícia, emocionalmente criada para atrair o público, não investigando as causas para o extermínio brutal de uma parlamentar que não tinha medo de defender seu povo em um país que se diz democrático. Não se pode deixar de lado que o capitalismo trabalha com a potência das narrativas e se apropria dela (BENTES, 2018, s/n), isso se mostrou na aparente comoção midiática sobre o fato e na não referência a intervenção militar no Rio de janeiro, algo muito debatido pela vereadora que era contra isso.

Tanto que dias antes de sua execução fez denúncias graves ${ }^{10}$ sobre essa intervenção, que agia com extrema violência, gerava e gera altos gastos econômicos e não resolve o problema. Após sua morte física, outras mortes se fizeram necessárias ao "equilíbrio do sistema opressor", a reentextualização/recontextualização da trajetória de Marielle como crime, trabalho viralizado por Fake News de pessoas consideradas “importantes e da lei". Mas porque recontar/reescrever a vida de Franco, por que ela deveria ser o alvo do ódio? Uma das defesas da vereadora eram os Direitos Humanos, no entanto, tais direitos, formulados incialmente, por pessoas legitimadas e escolarizadas, não conseguiram alcançar as intersecções de diferença que articula os vários Brasis. Pois esses são compostos por sujeitos com várias trajetórias que estão longe de serem vistas como o padrão do homem universal (que é a referência para a criação dos Direitos Humano formulado em contexto anglo-

10 Disponível em: https://theintercept.com/2018/03/17/essa-e-a-historia-dos-tres-crimes-que-marielle-francodenunciou-antes-de-morrer/. Acessado em: 27 de dezembro de 2018. 
europeu) portador do saber válido - europeu, heterossexual, cristão, escolarizado, de classe média-alta, perfil do colonizador.

A própria ideia de Humanidade, de quem é visto como humano e portador de direitos, não alcança os povos negros, historicamente objetificados à escravização, muito menos os povos indígenas, historicamente objetificados à selvageria e muito menos às mulheres que até os dias atuais trazem marcas que a subalternizam como sujeitos inferiores. Os Direitos Humanos não atuam de forma interseccional, apenas visualiza um sujeito ideal e silencia as necessidades daqueles lançados à margem social, que também são humanos, construíram a riqueza desse país, mas que não são representados nas instâncias de poder e nem são vistos como cidadãos que devem ter a oportunidade de falar sobre si mesmo.

Por isso, que quando nos deparamos como situações que tentam desmoralizar trajetórias de luta em favor do povo, que não é uma luta egoísta e que mexe com a estrutura da sociedade, a invasão que se tem ao contar a história desse outro fora das normas é feita de forma violenta, a forçando a retomar um lugar de inferioridade dado historicamente. E são narrativas que retomam a força da colonialidade do saber e do poder (QUIJANO, 2005) para massacrar todo o povo que Franco representa. Pois, se suspeitos no Brasil, geralmente, tem "a cara" de jovem negro, de periferia, não-escolarizado, empobrecido, a criminalização de quem defende o direito à vida desses sujeitos se torna consequência em um país estruturalmente racial.

Por isso, esse exercício de um olhar que procura pensar as interseccionalidades como forças atuantes em nossas vidas e em nossa trajetória de existência nos impulsiona à perspectiva decolonial (WALSH, 2009), de sair de nossas caixinhas conceituais e ampliar os horizontes para além do que nos é posto. A neurose racial do Brasil (GONZALEZ, 1984) é um processo constante que autoriza execuções em múltiplas instâncias de vidas antissistema. Isso tendo que o racismo no Brasil é algo estrutural ${ }^{11}$, é um elemento que articula os eixos de subalternizações que organiza e separa a sociedade ao mesmo tempo que defende uma homogeneidade fake. De forma que checar uma informação, escolher informações que potencializem sujeitos subalternizados e vertentes que valorizam a vida face a violência, nos posiciona em embate decolonial e interseccional entre as diferenças.

É preciso, então, diante dos múltiplos extermínios que Marielle-povo negro vem sofrendo se reexistir e se recriar junto a estratégias que sustentem nossos caminhos, pois

\footnotetext{
11 Disponível em: https://www.geledes.org.br/djamila-racismo-so-choca-quando-acontece-com-filha-do-brunogagliasso/. Acessado em: 25 de dezembro de 2018.
} 
"nossas lutas e corpos são a matéria dos sonhos, são a matéria do imaginário, e é isso que os novos movimentos políticos podem buscar. Esse é o novo ativismo que passa pela comoção e pelos afetos potentes, pela renovação da linguagem" (BENTES, 2018, s/n) e por outros usos da linguagem que visem não apenas ocupar espaços, mas transformá-los, e possibilitar que outros como nós também tenham condições efetivas de ocupar e transformar (RIBEIRO, 2015).

\section{Conclusões possíveis...}

Não serei interrompida... Marielle Franco

As Fake News sobre Marielle podem ser vistas como uma ferida constante e incisiva da colonialidade do poder/saber (QUIJANO, 2005) para a formulação de realidades que silenciam as diferenças. Isso aliado ao ato de matar, se torna um conjunto de armas organizadas para exterminar e apagar não apenas a fala projetada contra o sistema, mas também o corpo que fala, e ainda, o grupo do qual esse corpo negro, homossexual, favelado faz parte. Uma tentativa de lançar e/ou realinhar o outro ao seu "devido lugar" a partir da reconstrução da memória de uma história de vida, em momento instável e sensível, e invalidar/reduzir as ações de Franco como defensora da ampliação dos Direitos Humanos à favela.

As múltiplas mortes desse corpo coletivo, do qual Marielle era e é exemplo, perpassa para além da morte física, a execução simbólica, epistêmica, de saber popular, de interseccionalidade de diferenças, de produção de conhecimento acadêmico por mulheres negras. É o extermínio das raízes africanas, da ancestralidade, das pessoas que formam a base dessa sociedade, mobilizam ações sociais e políticas públicas para quem não se encaixa no padrão da existência legitima. Por isso, "quando as vidas negras realmente começarem a ter importância, isso significará que todas as vidas têm importância. E podemos também dizer especificamente que, quando as vidas das mulheres negras importam, então o mundo será transformado e teremos a certeza de que todas as vidas importam (DAVIS, s/p, 2017). Apesar de tudo, é preciso ressaltar que Marielle vive em cada mulher negra e em cada pessoa que tem os mesmos objetivos que ela e que buscam justiça para esses extermínios.

Assim, perceber que vários instrumentos são utilizados para a composição discursiva e do quanto isso pode não só reconstruir caminhos interpretativos sobre o outro, mas também reconstruir o que possa ser visto como verdade ou não, são questões das quais a naturalidade 
da modernidade se vale. O que aponta o quanto somos permeados por narrativas, especialmente midiáticas, que interferem em como devemos ver o mundo e nos alinhar ao olhar dominante, que usa a linguagem para promover e imprimir a violência não só simbólica, mas consequentemente, a física, como aponta os índices de mortes no país ${ }^{12}$. E, principalmente, é preciso que observemos quais extermínios realizamos no dia a dia, em nossas escolhas, em nossas leituras, em nossos julgamentos para que mais uma vez não venhamos a ser cúmplices do extermínio de Marielle-povo negro.

Quantos mais vão precisar morrer para que essa guerra acabe?

Marielle Franco

\section{Referências}

ALMEIDA, Marcos Vinícius e BTR, Carol. Ataque à imagem de Marielle Franco revela a lógica das Fake News. Revista Subjetiva. Medium. 2018. Disponível em: https://medium.com/revista-subjetiva/ataque-\%C3\%A0-imagem-de-marielle-franco-revela-a1\%C3\%B3gica-das-fake-news-f9c60999f07b. Acessado em: 20 de dezembro de 2018.

AUSTIN, John L. Performativo-constativo. Tradução: Paulo Ottoni. In: OTTONI, Paulo Roberto. Visão Performativa da linguagem. Campinas: Editora da Unicamp, 1998. 107-144.

BENTES, Ivana. Marielle: Operacões de mídia, anunciação e necropolítica. In: Revista Cult. Disponível em: https://revistacult.uol.com.br/home/marielle-operacoes-de-midianecropolitica/. Acessado em: 18 de dezembro de 2018.

BENVENISTE, Émile. Problemas de Linguística Geral I. Tradução Maria da Gloria Novak e Maria Luiza Neri. 2a edição. Campinas: Pontes Editora da Universidade Estadual de Campinas, 1988.

Problemas de Linguística Geral II. Tradução Eduardo Guimarães et al. $2^{a}$ edição. Campinas: Pontes Editores, 2006.

\footnotetext{
${ }^{12}$ Disponível em: http://www.ipea.gov.br/portal/images/170602_atlas_da_violencia_2017.pdf. Acessado em: 29 de dezembro de 2018.
} 
BUTLER, Judith P. Excitable speech: a politics of the performative. New York: Routledge, 1997. p. 1-41

CRENSHAW, Kimberle. A interseccionalidade na discriminação de raça e gênero. Revista de Estudos Feministas no 2. Universidade Católica de Salvador. 2002.

DAVIS, Angela. Transcrição da fala de Ângela Davis na Reitoria da Universidade Federal da Bahia no dia 25.7.2017. Centro de Estudos das Relações de Trabalho e Desigualdades. Disponível em: http://www.ceert.org.br/noticias/genero-mulher/18464/transcricao-da-faladeangela-davis-na-reitoria-da-universidade-federal-da-bahia-no-dia-2572017?fbcommentid= 1361670007286990_1361689173951740. Acessado em: 29 de dezembro de 2018.

GASPAR, Gabriel Rocha; NOVO, Maria Fernanda e OLIVEIRA, Vanessa. Violência como regra. Revista Cult. Disponível em: https://revistacult.uol.com.br/home/violencia-comoregra/. Acessado em: 25 de dezembro de 2018.

GONZALEZ, Lélia. Racismo e sexismo na cultura brasileira. Revista Ciências Sociais Hoje, Anpocs, p. 223-244, 1984.

GRAGNANI, Juliana. Marielle era uma das 32 mulheres negras entre 811 vereadores eleitos em capitais brasileiras. $B B C, 2018$. Disponível em: https://www.bbc.com/portuguese/brasil43424088. Acessado em: 25 de dezembro de 2018.

MARCUSCHI, Luiz. Produção textual, análise de gêneros e compreensão. São Paulo: Editora Parábola, 2008.

QUIJANO, Aníbal. Colonialidade do poder, eurocentrismo e América Latina. In: LANDER, Edgardo (org.). A colonialidade do saber: eurocentrismo e ciências sociais. Trad.: Julio Cesar Casarin Barroso Silva. Buenos Aires: Consejo Latinoamericano de Ciencias Sociais - Clacso, 2005.

RAMPINELLI, Waldir José. Tema 09 - Um genocídio, um etnocídio e um memoricídio. In: Revista Andes. 2014. Disponível em: http://www.andes.org.br/andes/print-revistaconteudo. andes?idRev=41\&idArt=212. Acessado em: 20 de dezembro de 2018.

RIBEIRO, Djamila. Brasil: onde racistas só se surpreendem com o racismo dos outros. Carta Capital. 2015. 
TIBURI, Marcia. Marielle Franco e o mal radical. Revista Cult. 2018. Disponível em: https://revistacult.uol.com.br/home/marielle-franco-e-o-mal-radical/.Acessado em: 20 de dezembro de 2018.

WALSH, C. Interculturalidad crítica y pedagogía de-colonial: apuestas (des)de el in-surgir, re-existir y re-vivir. 2009. 